\title{
DIMENSI DAN KOMPOSISI NEMATOSIT PADA KARANG SCLERACTINIA, Acropora florida DAN Acropora divaricata DI PANTAI MOTANDOI SELATAN KABUPATEN BOLAANG MONGONDOW SELATAN
}

(Dimensional and Composition of nematocytes in Scleractinia Coral, Acropora florida and Acropora divaricata at South Motandoi Beach, South Bolaang Mongondow Regency)

\author{
Sanjay Gagu ${ }^{1}$, Suria Darwasito ${ }^{1}$, Billy Th. Wagey ${ }^{1}$, Antonius P. Rumengan ${ }^{1}$, \\ Ari B. Rondonuwu ${ }^{2}$, Carolus P. Paruntu ${ }^{1^{*}}$ \\ 1) Program Studi IImu Kelautan, Fakultas Perikanan dan IImu Kelautan, Universitas Sam Ratulangi, \\ Manado 95115 Sulawesi Utara, Indonesia. \\ 2) Program Studi Manajemen Sumberdaya Perairan, Fakultas Perikanan dan IImu Kelautan, \\ Universitas Sam Ratulangi Manado 95115 Sulawesi Utara. \\ *Corresponding author: carolusparuntu@yahoo.com
}

The purpose of this study was to determine the type, dimensions and composition of nematocytes in Scleractinia, Acropora florida and Acropora divaricata. This research was conducted in South Motandoi Beach, East Pinolosian District, South Bolaang Mongondow Regency, North Sulawesi for five (5) months; from February to June 2019. The method of this research was observation using student-t statistical data analysis. Microbasic p-Mastigophore type-II (MpM-II) and Holotricous isorhiza $(\mathrm{HI})$, while $A$. divaricata only has type-II Microbasic p-Mastigophore (MpM-II) nematocytes. The nematocytes dimension showed an average capsule length of MpM II in A. florida of was $262.32 \mu \mathrm{m}$ and $A$. divaricata was $125.15 \mu \mathrm{m}$, mean capsule width of MPM II in A. florida was $67.01 \mu \mathrm{m}$ and $A$. divaricata was $31.95 \mu \mathrm{m}$, and the average length of $\mathrm{mpM} \mathrm{II} \mathrm{on} A$. florida was $154.44 \mu \mathrm{m}$, and $A$. divaricata was $70.97 \mu \mathrm{m}$. Nematocytes composition showed that MPM II in A. florida was $95.56 \%$ and $\mathrm{HI}$ was $4.44 \%$, while the composition of MPM II nematocytes in A. divaricata was $100 \%$ and $\mathrm{HI}$ was $0 \%$. Student t-test showed that the ratio of 2 average values of capsule length, capsule width, and MPM II stem length from two populations of $A$. florida and $A$. divaricata were not significantly different $(P>0.05)$. It can be concluded that both types of $A$. florida and $A$. divaricata corals have different types and composition of nematocytes however their size dimensions are not significantly different. Further studies are important to examine genetic and environmental factors to find out how much the kinship relationship between the two types of those coral.

\footnotetext{
Keywords: Acropora florida, Acropora divaricata, HI, Scleractinia coral, MpM II, nematocytes

Tujuan penelitian adalah untuk mengetahui tipe, dimensi dan komposisi nematosit pada karang Scleractinia, Acropora florida dan Acropora divaricata. Penelitian ini dilkakukan di Pantai Motandoi Selatan Kecamatan Pinolosian Timur Kabupaten Bolaang Mongondow Selatan Provinsi Sulawesi Utara selama 5 bulan, Februari-Juni 2019. Metode penelitian adalah observasi dengan menggunakan analisis data statistik $t$-student. Hasil peneltitan memperlihatkan bahwa A. florida memiliki dua tipe nematosit yaitu microbasic p-mastigophore tipe-II (MpM-II) dan holotricous isorhiza (HI), sedangkan A. divaricata hanya memiliki tipe nematosit microbasic p-mastigophore tipe-II (MpMII) saja. Dimensi nematosit memperlihatkan rata-rata panjang kapsul MpM II pada A. florida sebesar 262,32 $\mu \mathrm{m}$ dan A. divaricata 125,15 $\mu \mathrm{m}$, rata-rata lebar kapsul MpM II pada A. florida sebesar 67,01 $\mu \mathrm{m}$ dan A. divaricata 31,95 $\mu \mathrm{m}$, dan rata-rata panjang tangkai MpM II pada A. florida sebesar 154,44 $\mu \mathrm{m}$, dan A. divaricata 70,97 $\mu \mathrm{m}$. Komposisi nematosit memperlihatkan bahwa MpM II pada A. florida sebesar 95,56\% dan HI 4,44\%, sedangkan komposisi nematosit MpM II pada A. divaricata sebesar $100 \%$ dan $\mathrm{HI} 0 \%$. Uji t-student memperlihatkan bahwa perbandingan 2 nilai rata-rata panjang kapsul, lebar kapsul, dan panjang tangkai MpM II dari dua populasi A. florida dan A. divaricata tidak berbeda nyata $(P>0,05)$. Kesimpulan kedua jenis karang $A$. florida dan A. divaricata mempunyai tipe, komposisi dan dimensi nematosit yang serupa. Studi lanjut penting untuk meneliti faktor genetik dan lingkungan hidupnya untuk mengetahui seberapa besar hubungan kekerabatan antara kedua jenis karang tersebut.
}

Kata kunci: Acropora florida, Acropora divaricata, HI, karang Scleractinia, MpM II, nematosit 


\section{PENDAHULUAN}

Karang keras Scleractinia adalah salah satu jenis karang pembentuk ekosistem terumbu karang yang utama. Scleractinia pada umumnya mampu mendeposit kapur (CaCO3) yang berfungsi sebagai kerangka hewan karang (Luthfi, 2003). Pada filum cnidaria memiliki organel-organel intraseluler dalam jaringan tubuh di bagian terluar, yaitu cnidae yang melepaskan keluar tubuhnya jika ada suatu rangsangan dari lingkungan tersebut. Cnidae dipergunakan untuk melawan predator dan menangkap mangsa yang menyerang fauna cnidaria lainnya yang berada di sekitarnya, atau untuk melekatkan tubuhnya pada suatu substrat selama proses setelmen (Watson dan Wood 1998). Cnidae yang terdapat dalam sebuah sel dapat disebut cnidocyte. Cnidae dibagi dalam tiga kelompok utama yaitu nematosit, ptikosit dan spirosit (Mariscal1984; Watson dan Wood, 1988).

\section{Pires dan Pitombo}

mengatakan bahwa semua tipe-tipe yang berbeda pada umumnya sudah dianggap sebagai suatu karakter yang berguna dalam taksonomi dari perbedaan ordoordo cnidarian. Sebagai suatu masalah dalam penggunaan yang berbeda dari nematosit suatu taksonomi karang yaitu komposisi nematosit perbedaan diantara organ-organ yang berbeda tergantung pada perkembangan dan fisiologis (Fautin, 1998). Hidaka dkk. (1984) melaporkan perbandingan morfologi nematosit antara hard morph dan soft morph Galaxea fascicularis dan antara Stylophora pistilata dan Stylophora mordax adalah berbeda nyata, dan disarankan spesies-spesies tersebut adalah spesies yang berbeda. Lang (1986) melaporkan berbagai macam tipe nematosit telah digunakan untuk taksonomi karang Scleractinia. Paruntu (1997) melaporkan nematosit dalam keaadaan belum melepaskan tangkai dan benang dari kapsulnya (undischarged nematocysts) dan dalam keadaan melepaskan tangkai dan benang dari kapsulnya (discharged nematocysts) dari mesentrial filament Pachyseris rugosa.
Paruntu dkk. (2000) melaporkan perbedaan karakteristik nematosit pada fase perkembangan Pocillopora damarcornis, yaitu mulai dari planula, polip utama, koloni muda dan koloni dewasa.

Paruntu dkk. (2013) melaporkan Pocillopora eydouxi, Pocillopora woodjonesi, dan Pocillopora verucosa memiliki komposisi dan dimensi nematosit yang berbeda, dan disarankan ketiga spesies tersebut merupakan spesies yang berbeda. Paruntu dkk. (2014) melaporkan tipe dan morfologi nematosit dari dua spesies karang Scleractinia, Seriatopora hystrix dan Seriatopora caliendrum.

Berdasarkan latar belakang di atas bagaimanapun jenis karang Scleractinia, $A$. florida dan $A$. divaricata belum pernah diteliti sampai sekarang ini tentang biologi nematositnya. Penelitian ini bertujuan untuk mengamati tipe, dimensi dan komposisi nematosit pada karang Scleractinia, A. florida dan $A$. divaricata di terumbu karang Pantai Motandoi Selatan Kabupaten Bolaang Mongondow Selatan.

\section{METODE PENELITIAN}

\section{Tempat dan Waktu Penelitian}

Pengambilan sampel karang A. florida dan $A$. divaricata dilakukan di perairan Pantai Motandoi Selatan Kecamatan Pinolosian Timur, Kabupaten Bolaang Mongondow Selatan, Provinsi Sulawesi Utara (Gambar 1). Selanjutnya sampel diteliti di Labotorium Biologi Kelautan Program Studi IImu Kelautan, Fakultas Perikanan dan IImu Kelautan dan di Labolatorium Biologi Molekuler Program Studi Farmasi Fakultas Matematika dan IImu Pengetahuan Alam Universitas Sam Ratulangi. Adapun waktu penelitian direncanakan akan dilakukan selama 5 bulan, dari Februari - Juni 2019.

\section{Alat dan Bahan}

Peralatan yang digunakan dalam penelitian ini snorkel, pahat, mikroskop optika view tipe 4083 B3, gelas ukur, pinset, pipet, slide glass, cover glass, 
toples wadah sampel yang berisi larutan asetat $10 \%$ dan alkohol $70 \%$.

aplikasi optika view 7. Bahan yang digunakan adalah koloni karang $A$. florida dan $A$. divaricata, formalin $10 \%$, asam
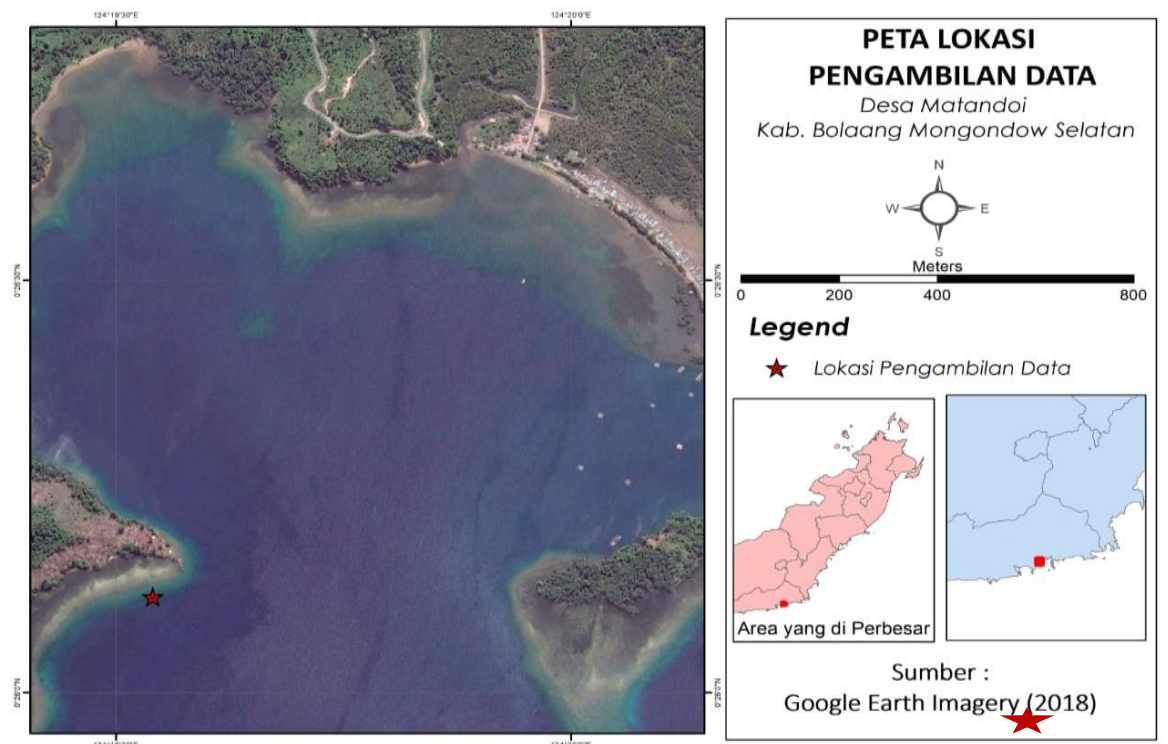

Gambar 1. Peta pengambilan sampel ditandai dengan

\section{Prosedur Penelitian}

Sampel karang $A$. florida dan A. divaricata diambil di area terumbu karang perairan Motandoi Selatan. Pengambilan sampel karang uji dengan menggunakan alat snorkel dan pahat untuk memperoleh koloni karang. Setiap jenis karang diambil tiga koloni dengan ukuran diameter kira-kira $5 \mathrm{~cm}$. Identifikasi karang dilakukan di Laboratorium Biologi Kelautan FPIK Unsrat untuk mengetahui jenis karang dengan menggunakan buku identifikasi Veron (2000) Gambar 2.

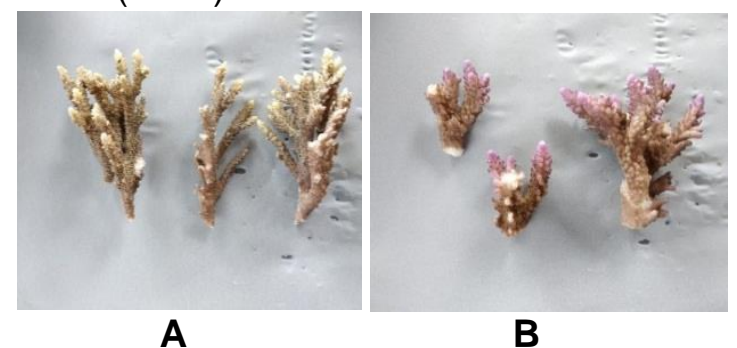

Gambar 2. Jenis karang uji.

Keterangan: A. Acropora florida

B. Acropora divaricata

Selanjutnya, sampel karang uji diawetkan dengan alkohol $70 \%$ dalam toples untuk pengawetan. Sampel karang uji didekalsifikasi dalam larutan formalin
$10 \%$ dan asam asetat $10 \%(1: 1)$ selama 3 hari untuk menghancurkan skeleton karang dan memperoleh jaringan tubuh karang yang lunak. Sampel karang dibawa ke Labolatorium Biologi Molekuler Program Studi Farmasi Unsrat untuk diuji mengenai tipe, dimensi dan komposisi nematosit.

\section{Pengamatan Nematosit}

Setelah proses dekalsifikasi, jaringan tubuh karang yang lunak dari setiap jenis karang diambil potongan kecil dengan menggunakan pinset dan diletakkan di dalam wadah petridis yang berisi air tawar. Selanjunya, potongan kecil tersebut dihisap dengan pipet dan diletakkan di atas slide glass, ditutup dengan cover glass, dan dilumatkan dengan bantuan alat seperti pensil sampai nematosit terlihat dengan jelas di bawah mikroskop. Sel nematosit diambil foto melalui mikroskop (Optika 4083 B3) dengan menggunakan lensa objektif pembesaran x100 digunakan untuk mengamati tipe dan dimensi nematosit. Tipe nematosit diidentifikasi dengan menggunakan buku Mariscal (1974), sedangkan untuk mengukur dimensi nematosit dengan menggunakan aplikasi 
Optika view7 dalam komputer yang dihubungkan dengan mikroskop.

\section{Pengukuran Dimensi Nematosit}

Dimensi nematosit, yang diukur adalah panjang kapsul, lebar kapsul dan panjang tangkai. Panjang dan lebar kapsul diukur mulai dari ujung kapsul yang satu ke ujung kapsul yang lain bagian terluar, sedangkan panjang tangkai diukur dari ujung nematosit yang satu sampai pada ujung tangkai yang berbentuk seperti huruf "V" (Gambar 2). Satuan yang digunakan dalam pengukuran dimensi nematosit adalah mikro meter $(\mu \mathrm{m})$.

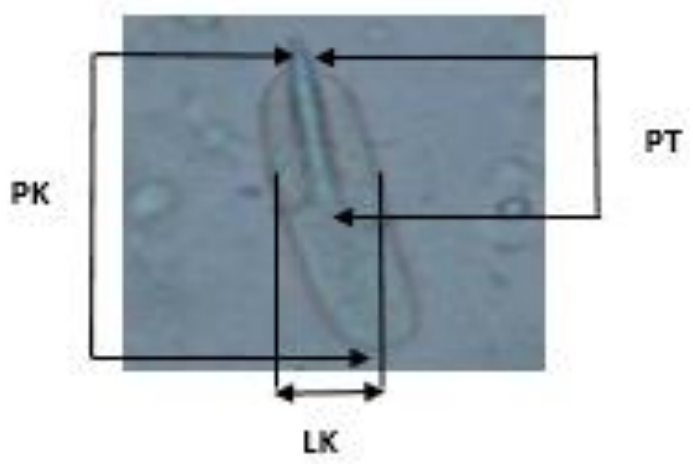

Microbasic p-mastigophore tipe II

Gambar 2. Cara pengukuran dimensi nematosit dalam keadaan belum melepaskan tangkai dan benang dari kapsulnya.

Keterangan: $\mathrm{PK}=$ Panjang kapsul; LK = Lebar kapsul; PT = Panjang tangkai.

\section{Komposisi Nematosit}

Komposisi nematosit diukur pada tipe-tipe nematosit utama saja, sedangkan tipe nematosit yang minor diabaikan, karena sulit untuk diidentifikasi dan dihitung. Untuk keperluan perhitungan komposisi nematosit setiap jenis karang, maka setiap tipe nematosit, jumlahnya dihitung paling sedikit pada 3 cetakan foto dan paling banyak 10 cetakan foto yang diambil dari setiap koloni uji paling sedikit 13 sel setiap tipe nematosit yang dihitung dalam setiap koloni sampel dalam setiap spesies karang yang diuji.

\section{Analisis Data}

Untuk membandingkan apakah terdapat kesamaan atau perbedaan di antara ke dua spesies yang diteliti berdasarkan dimensi nematosit (panjang kapsul, lebar kapsul dan panjang tangkai) yang diukur, maka uji-t (t-student) dilakukan untuk menguji perbedaan 2 rataan populasi karang uji. Nilai signifikan yang digunakan dalam uji statistik ini adalah $\mathrm{P}=0,05$.

\section{HASIL DAN PEMBAHASAN}

Hasil penelitian di atas didapatkan bahwa jenis karang $A$. florida memiliki dua tipe nematosit yaitu MpM II dan $\mathrm{HI}$, sedangkan $A$. divaricata hanya memiliki satu tipe nematosit yaitu MpM II. MpM II ditemukan paling dominan, yaitu hampir $100 \%$ dibandingkan $\mathrm{HI}$ pada karang $A$. florida, sedangkan $A$. divaricata hanya memiliki satu tipe nematosit utama yaitu tipe MpM II. Tipe MpM II ditandai dengan panjang tangkainya mencapai kira-kira $2 / 3$ dari $A$. florida dan $A$. divaricata dapat dilihat pada Gambar 3 dan 4.

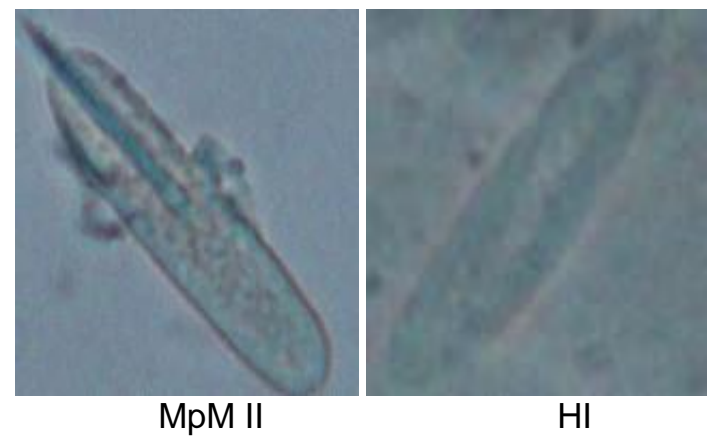

Gambar 3. Tipe nematosit $\mathrm{MpM} \|$ dan $\mathrm{HI}$ A. florida dengan pembesaran x100 lensa objektif.

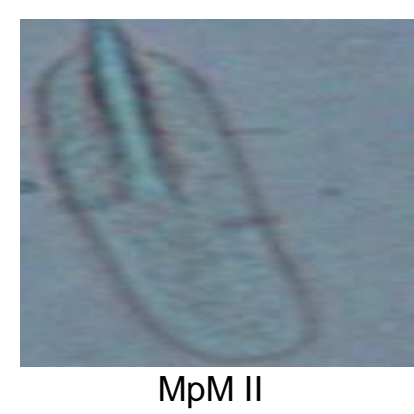

Gambar 4. Tipe nematosit MpM II A. divaricata dengan pembesaran $x 100$ lensa objektif. 


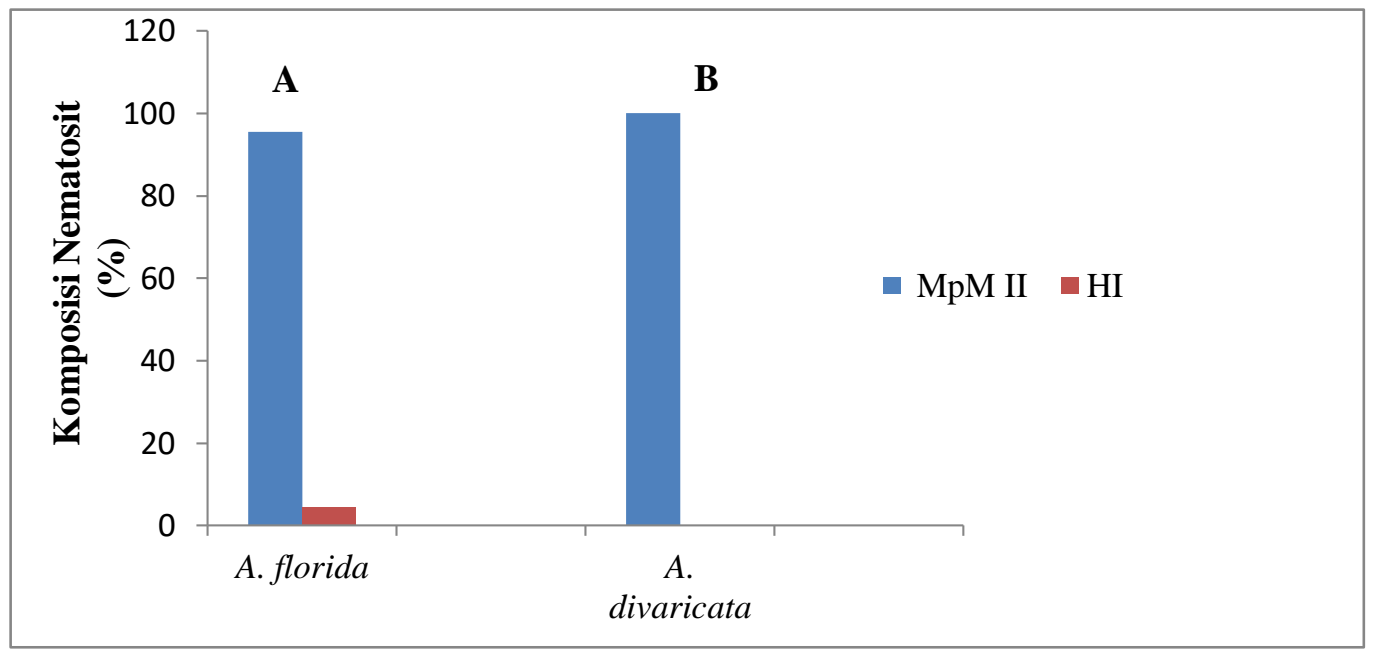

Gambar 5. Komposisi nematosit (\%) A. florida dan A. divaricata

Gambar 5 memperlihatkan bahwa komposisi nematosit MpM II pada $A$. florida sebesar 95,56 \% dan $\mathrm{HI} 4,44 \%$, sedangkan komposisi nematosit MpM II pada $A$. divaricata sebesar $100 \%$ dan $\mathrm{HI}$ $0 \%$.

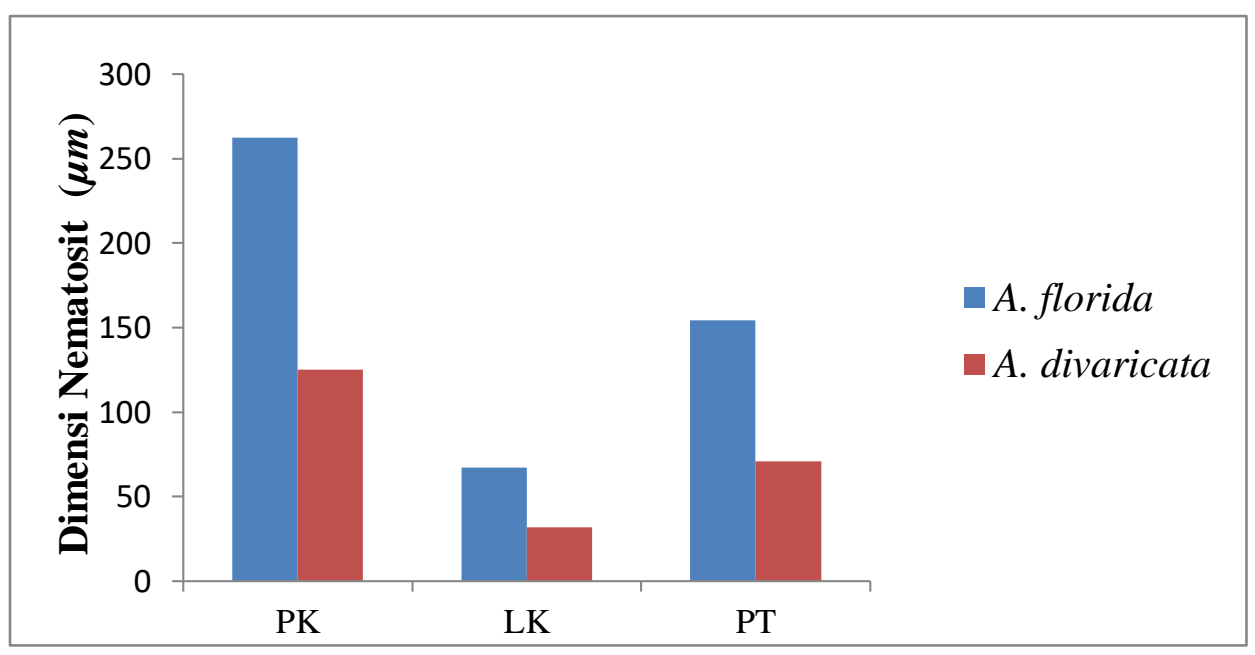

Gambar 6. Perbandingan dimensi nematosit tipe nematosit MpM II antara A. florida dan A. divaricata.

Keterangan: $\mathrm{PK}=$ Panjang kapsul; LK= Lebar kapsul; PT = Panjang tangkai.

Gambar 6 memperlihatkan bahwa rata-rata panjang kapsul MpM II pada A. florida sebesar 262,32 $\mu \mathrm{m}$ dan A. divaricata 125,15 $\mu \mathrm{m}$, rata-rata lebar kapsul MpM II pada $A$. florida sebesar $67,01 \mu \mathrm{m}$ dan $A$. divaricata 31,95 $\mu \mathrm{m}$ dan rata-rata panjang tangkai MpM II pada A. florida sebesar 154,44 $\mu \mathrm{m}$ dan A. divaricata 70,97 $\mu \mathrm{m}$. Uji t-student memperlihatkan bahwa perbandingan 2 nilai rata-rata panjang kapsul, lebar kapsul, dan panjang tangkai MpM II dari dua populasi $A$. florida dan $A$. divaricata tidak signifikan atau tidak berbeda nyata $(P>0,05)$.

Berdasarkan hasil penelitian di atas bahwa MpM II ditemukan paling dominan, yaitu hampir $100 \%$ dibandingkan $\mathrm{HI}$ pada karang A. florida, 
sedangkan $A$. divaricata hanya memiliki satu tipe nematosit utama yaitu tipe MpM II. Tipe MpM II ditandai dengan panjang tangkainya mencapai kira-kira $2 / 3$ dari panjang kapsulnya, sedangkan tipe MpM I ditandai dengan panjang tangkainya mencapai sekitar atau lebih kecil dari panjang kapsulnya. Hidaka (1991) menyatakan bahwa MpM pada umumnya terdistribusi dalam tentakel-tentakel dari koloni-koloni karang dewasa. Paruntu (1996) memberikan informasi bahwa tipe nematosit microbasic p-mastigophore (MpM) digunakan oleh karang untuk agresi dan mematikan mangsa/predator jika ada gangguan dari lingkungan perairan sekitarnya, dimana Acropora ini hidup. MpM II dari $A$. florida dan $A$. divaricata diduga digunakan oleh tentakel untuk memperoleh makanan dan mempertahankan diri dari serangan predator. Paruntu dkk. (2000) telah menemukan tipe-tipe nematosit pada karang $P$. damarconis, yaitu tipe holotirchous isorhiza besar ( $\mathrm{HI}$ besar), holotrichous isorhiza kecil ( $\mathrm{HI}$ kecil), microbasic b-mastigophore (MbM), microbasic p-mastigophore tipe-I (MpM I) dan microbasic p-mastigophore tipe-II (MpM II). Jadi kedua jenis karang dari genus Acropora memiliki tipe sel nematosit yang spesifik yaitu microbasic p-mastigophore tipe-II (MpM II), sedangkan tipe $\mathrm{HI}$ kehadiran dan perannya dapat diabaikan karena sangat minor.

Sel nematosit yang ditemukan pada masing-masing karang uji, $A$. florida dan $A$. divaricata baik dari panjang kapsul, lebar kapsul, dan panjang tangkai bahwa A. florida lebih besar dimensinya dibandingkan dengan $A$. divaricata. Bagaimanapun setelah dilakukan uji statistik dengan mengunakan t-student menghasilkan bahwa panjang kapsul, lebar kapsul dan panjang tangkai dari kedua jenis karang tersebut tidak berbeda nyata.

\section{KESIMPULAN}

Kedua jenis karang, $A$. florida dan A.divaricata dapat disimpulkan mempunyai tipe, komposisi dan dimensi nematosit yang serupa (tidak berbeda nyata). Studi lanjut dapat dilakukan pada kedua jenis karang ini mengenai faktor genetik dan lingkungan hidupnya untuk mengetahui seberapa besar hubungan kekerabatan antara kedua jenis karang tersebut.

\section{DAFTAR PUSTAKA}

Beckman, A. dan Ozbek, S., 2012. The Nematocyst: A Molecular Map of the Cnidarian Stinging Organelle. Int. J. Dev. Biol. 56:577 - 582 .

Fautin, D.G., 1988. Importance of Nematocyst to Actinian Taxonomy. Hal. 487-500. In Hessinger, D.A. and H.M. Lenhoff (eds). The Biology of Nematocyst. Academy Press. Inc. San Diego.

Fautin, D.G., 2009. Structural Diversity, Systematics, and Evolution of Cnidae. Toxicon 54: 1054-1064. 11 hal.

Google Earth Imagery 2018.

Hidaka, M. dan Yamazato, K., 1984. Intraspecific Interaction in a Scleractinian Coral, Galaxea fascicularis - Induced Formation of Sweeper Tentacles. Coral Reefs, 3 (2), 77-85.

Hidaka, M. dan Yamazato, K., 1985. Color Morph of Galaxea fascicularis found in the Reef around the Sesoko Marine Science Centre. Galaxea, 4: 33-35.

Hidaka, K., 1991. Use of Cnidae Morphology in Taxonomy of Corals. Graduation Thesis. University of the Ryukyus.

Lang, J.C., 1984. Whatever Works: The Variable Importance of Skeletal and Non-skeletal Character in Scleractinian Taxonomy. Palaeontogr. Amer., 54: 18-44.

Lang, J.C., 1986. Whatever Works: The Variable Importance of Skeletal and Non-skeletal Character in 
Scleractinian

Taxonomy.

Palaeontogr. Amer., 54: 18-44.

Luthfi, O.M., 2003. Sebaran Spasial Karang Keras (Scleractinia) di Perairan Pulau Panjang, Jepara. Fakultas Perikanan dan IImu Kelautan Universitas Diponegoro, Semarang. 116 hal.

Mariscal, R.N., 1974. Nematocyst. In Muscatine, L. and H. M. Lenhoff (eds). Coelenterates Biology: Reviews and New Perspective. Academy Press. New York. Hal. 129-178.

Mariscal, R.N., 1984. Cnidaria: Cnidae. In Bereiter-Hahn J, Matoltsy AG, Richards KS (eds) Biology of the Integument, Vol. 1. Invertebrates. Springer, Berlin Heidelberg New York, pp 57-68.

Paruntu, C.P., 1996. Studies on Cnidae of Scleractinian Corals: Development Changes in Cnida Composition and Spatial Distribution of Cnidae along Mesenterial Filaments. Master Thesis. University of Ryukyus Okinawa Japan. P. 1-58.

Paruntu, C.P., 1997. Spatial distribution of cnidae along mesentrial filament of Pachyseris rugosa. Berita Fakultas Perikanan. UNSRAT. 5 (12).

Paruntu, C.P., Hidaka, K., dan Hidaka, M., 2000. Developmental Changes in Cnidae Composition of the Coral Pocillopora damicornis. Galaxea, JCRS. Japan. 2 : 23-28.

Paruntu, C.P., Rifai, H., dan Kusen, J.D., 2013. Nematosit dari Tiga Spesies Karang Scleractinia, Genus Pocillopora (Nematocysts of the Three Scleractinian Corals of Genus Pocillopora). Jurnal Perikanan dan Kelautan Tropis. Vol. IX, No. 2. Hal. 60-64.

Paruntu, C.P. dan Souw, N., 2014. Morfologi Nematosit dari Dua
Karang Scleractinia, Seriatopora hystrix dan Seriatopora caliendrum Jurnal LPPM Bidang Sains dan Teknologi, Vol. 1, No. 1. Hal. 113120.

Pires, D.O. dan Pitombo, F.B., 1992. Cnidae of the Brazillian Mussidae (Cnidaria : Scleractinia) and Their Value in Taxonomy. Bull, of Mar, Sci. 51:(2) 231-244.

Veron, J.E.N., 2000. Coral of the World. Edited by Mary Stafforf Smith. Australian Institute of Marine Science. Townsville. Australia.

Watson, G.M. dan Wood, R.L., 1988. Colloqioum on Terminology. Hal. 2123. In: Hessinger, D.A. and H.M. Lenhoff (eds). The Biology of Nematocyst, Academic Press Inc. San Diego.

Wells, S.W., 1956. Scleractinia. In Moore R.C. (Ed.) Treatise on invertebrate Paleontology. Coellenterate (Part F). Geol. Soc. Americand Kansas Press.328-344.

Wallace, C.C., dan Wolstenholme, J., 1998. Revision of the Coral Genus Acropora (Sclerentina: Astrocoeniina: Acroporidae) from Indonesia. Zool. J. Linnean Soc. 123: 199-384. 